\title{
The oak or the reed: how resilience theories are translated into disaster management policies
}

\author{
Caroline Wenger ${ }^{1,2}$
}

\begin{abstract}
Although many researchers explore disaster resilience as an ongoing process or as a measurable property with indicators, few study whether disaster resilience policies are likely to lead to outcomes that are adaptive over the longer term. Some measures intended to increase local resilience may actually decrease the ability to cope with large-scale disasters. In the context of flood management, this work looks at activities supported in the name of resilience and whether they will result in long-term adaptive outcomes. It is proposed that the interpretation of "resilience" in emergency management has been influenced by pre-existing disaster management concepts, such as the prevent-prepare-respond-recover (PPRR) framework. These have not been adequately reassessed in the light of resilience theories. Disaster resilience was examined using the PPRR framework as a lens. With a focus on flooding, national disaster resilience policy documents from four countries and the global arena were studied to find out which activities were linked to resilience and whether this varies between countries. Subnational policies were also examined in areas that had recently experienced major flooding. Resilience interpretations in some countries were found to support resistance strategies while others were more accommodating. The continued development of floodplains, facilitated by structural mitigation, is an example of a highly resilient but maladaptive feedback loop. This results in risk accumulation and higher consequences during extreme floods. Research explores ways interventions could alter feedbacks and transform to more desirable resilience regimes. It is proposed that negotiating long-term adaptation pathways should be the ultimate aim for planners and emergency managers rather than resilience, which tends to support the status quo. Emergency management concepts and frameworks need to be amended in the light of resilience theories to make it easier to achieve adaptive outcomes.
\end{abstract}

Key Words: climate change adaptation; disasters; ecosystem-based approaches; flood management; levees; resilience

\section{INTRODUCTION}

Resist or accommodate?

In perhaps one of the oldest tales of disaster resilience, ancient Greek storyteller, Aesop, set the oak against the reed in a contest of survival. The oak stood proud and unbending against storms and mocked the reed for being pushed by every breeze. One day a storm of unprecedented magnitude whipped up. Overcome, the inflexible oak was uprooted and died. However, the reed humbly bowed and once the storm passed, sprang back up. This tale illustrates the folly of rigid resistance and the wisdom of acknowledging and accommodating powerful forces. It is also a tale that lends itself to the modern era of climate change, in which "unprecedented" weather events are increasingly likely.

Resilience theorists today continue to debate the opposing elements of resistance and stability versus pliability, change, and adaptability and the property of "bounce back" displayed by the reed. As an engineering term, resilience is defined by the speed with which the object returns to a stable state or equilibrium (Bodin and Wiman 2004) and it incorporates robustness: the ability to both resist stress (rigidity) and absorb it (ductility; Alexander 2013). The engineering characterization of resilience has been used by disaster management theorists, including Mileti (1999) and Norris et al. (2008). Operational disaster resilience definitions often reflect engineering resilience, when they use words such as "resist," "withstand," and "rapid recovery" (Wenger 2017).

However, some disaster researchers have drawn attention to a fundamental opposition between the concepts of resistance and resilience, particularly when applied to social-ecological systems (de Bruijn 2004, Liao 2012, Reghezza-Zitt et al. 2012). The battle of semantics had its origin in Holling's seminal work that applied the concept of resilience to ecological systems (Holling 1973). He felt that resilience was best described by the persistence of a system and the relationships between state variables, and not by its stability, which paradoxically, could lead to extinction. The most resilient systems, he argued, are often highly unstable, characterized by major fluctuations of system elements. This interpretation is felt to better reflect the complex and unpredictable interactions and feedbacks between ecological and social systems (Walker and Salt 2006).

Holling's focus was on the long-term survival of an ecological "system" despite (or because of) the fluctuations of component populations and conditions over time. However, this ecological perspective is problematic when transferred to social-ecological systems in general and disaster management in particular, because the fluctuation of human populations (or of elements on which humans depend) is not a tolerable view of resilience from a human perspective. Enabling the human component of the system to prosper is paramount. In a social-ecological system, this means maintaining human stability (population numbers, health, infrastructure, resource base, networks, and social institutions) in the face of variable conditions. Human stability can be achieved either through artificially maintaining a stable state (using resistance strategies), or through the ability to operate under fluctuating conditions (using accommodation strategies). The latter requires human flexibility and adaptation, and sometimes the manipulation of system feedbacks. 
A resistant, stable system prevents change from occurring up until the point where resistance is overcome. However, stability erodes resilience in two ways. First, it allows risks to accumulate. This means that when a large magnitude event occurs (overcoming resistance) it has greater impact, increasing the chance of a shift to an undesirable regime. Gunderson (2010) offers the ecological example of fuel build up in a forest where fires are suppressed. Applied to flooding, an artificially stable, dry system could enable inappropriate development to build up in a hazardous area.

Second, by preventing exposure to disruption, stability results in a system that can only operate in the "stable state." Stable conditions enable greater efficiency (less redundancy) and lead to an increasingly narrow operating space. Such communities forfeit the ability to function outside of this state, which increases their vulnerability to large-scale events. Lack of exposure prevents learning from lesser events, which also inhibits adaptation. In Liao's (2012) example, a levee creates a stable system that can only operate in dry conditions. Exposure prevention lowers risk awareness and response capacity. It also inhibits the use of construction standards that are flexible enough to cope with floods. Leveed areas may be excised from "official" floodplains resulting in the absence or regression of flood-related construction or insurance requirements (ILPRC 2006, Keogh et al. 2011). Similarly, Bohensky and Leitch (2014) link flood mitigation dams with reduced ability to learn from past events and continuing development of unsafe areas.

Some observe the crucial role of exposure to lesser events in enabling communities to become self-reliant and adapt (Baan and Klijn 2004, Liao 2012, Zebrowski, 2013, Engel et al. 2014). A related observation is that resilience is unlikely to develop in the absence of vulnerability, exposure being a component of vulnerability (Gallopín 2006, Reghezza-Zitt et al. 2012). However, in the disaster risk management sector, hazard exposure is most commonly viewed as a negative element that increases risk (e.g., QRA 2012, AGD 2013, USACE 2013).

In this paper I explore how resilience is applied operationally in four countries and the policy outcomes it supports, including resistance versus accommodation strategies. I also provide an overview of resilience theories relevant to emergency management including the shortcomings of the prevent-prepare-respondrecover (PPRR) framework and how it was revised for data analysis. A particular concern in relation to resistance strategies is that they support the continuing development of floodplains, placing more people at risk and damaging natural resources on which societies depend (Tockner et al. 2008). In a feedback loop that could be described as an undesirable resilience regime, this fuels future demand for structural mitigation, which in turn supports additional development of hazardous areas (Smith 1998). Hence a key issue for this paper is whether resilience policies support this maladaptive feedback loop or whether they support transformation out of it. I assess (1) how useful the concept of resilience is for emergency management; (2) whether it should guide emergency management policy or be replaced; and (3) if it needs replacing, what should replace it.

\section{Resilience and adaptability}

Resilience of social-ecological systems (SES) is often viewed in terms of adaptive capacity (e.g., Barnett 2001, Folke 2006, Norris et al. 2008). This is reinforced by ideas such as "bounce forward"
(Manyena et al. 2011) that frame resilience as a process of continual improvement.

However, adaptive capacity is an imprecise term. Adaptation comes in many different forms and it is not always clear which is meant. Adaptation may be reactive, addressing obvious deficiencies through incremental adjustments, or it can question underlying values and structures, acknowledge the inevitability of large-scale change, and aim for managed transformation (IPCC 2014). Either may be valid, depending on the potential magnitude of the problem and trade-offs involved.

In practice, "bounce forward" is often limited to upgrade. Although this may be more sensible than reinstatement to prior standards, it remains an incremental measure, intended to maintain continuity during and following disasters. A ministerial funding announcement illustrates this point: "Adelaide Street will be raised by $300 \mathrm{~mm}$ and upgrades to storm water drainage will be made to improve flood resilience to a gauge level of 11.4 metres" (Crisafulli 2014a).

In this example, resilience is quantifiable and equates to water depth. It is a classic example of single loop learning (IPCC 2012) and there is no suggestion of a new way of thinking or approach that might ultimately prove more adaptive. Incremental change at the margins "is possibly the most dangerous path: a relief valve that gives the appearance of change and alleviates symptoms for a time" (Handmer and Dovers 1996:506). This may reinforce the status quo and path dependencies that lock future decisions into a maladaptive space (Barnett and O'Neill 2010, Wise et al. 2014), a key concern of this paper.

A further issue is the ability to negotiate trade-offs between timescales, social groups, and regions (IPCC 2014, Chelleri et al. 2015). Encapsulated by resilience theorists in the question: "resilience of what to what?" (Carpenter et al. 2001), this is a challenging issue for operationalizing resilience, and ensuring that "improvements" do not inadvertently result in maladaptation (Barnett and O’Neill 2010).

Adaptation that supports a resilient status quo does not lead to long-term resilience if it merely delays change and accumulates risks for the future. Resilience needs to support adaptation options that look to broader scales in space and time, across sectors and social groups (Adger et al. 2005). It is therefore important, when looking at disaster resilience interpretations, to be able to distinguish whether policies support resistance, incremental or transformational change. If resilience is underpinned by adaptive capacity, this should explicitly include transformational capacity, the ability to move to a more desirable resilience regime. Otherwise there is a risk that politicians, practitioners, and the public may interpret "ability to adapt" as narrow, reactive incrementalism. This is in line with other authors who have highlighted a need for SES resilience to incorporate transformative approaches to deliberately move to a new development trajectory, including Folke et al. (2010), Chelleri and Olazabal (2012), Elmqvist (2014) and Matyas and Pelling (2015).

\section{Transfer to emergency}

The concept of resilience has transferred across many disciplines, including engineering, psychological health, ecological systems, and most recently, disaster management (Alexander 2013). The idea of resilience has been used in emergency literature since the 
1970s but its meaningful interpretation in the context of disasters began almost a decade later (Torry 1979, Wildavsky 1988, Handmer and Dovers 1996). Disaster resilience finally emerged on the political stage following the 11 September 2001 terrorist attacks in the United States, with the formation of Britain's London Resilience Partnership and UK Resilience (LRRF 2006, Alexander 2013). Resilience has since become a key disaster management concept and has received international prominence through the United Nations International Strategy for Disaster Reduction and the Hyogo and Sendai Frameworks (UNISDR 2005, UNISDR 2015a).

When adopted into operational disaster management, resilience was superimposed upon pre-existing concepts and operational frameworks. Although the differences between resilience and the concept of vulnerability have been well explored, there has been less examination of the relationship between resilience and the PPRR framework.

The PPRR framework originated in the USA as "Comprehensive Emergency Management" in response to the fragmentation of emergency management. There, a strong separation was observed between fast-action, operational "preparation-response" phases and the evaluative, policy making style of management required for mitigation and long-term recovery. Planning, funding, and legislation for "mitigation-recovery" were ad hoc, while the agencies and programs implementing them were uncoordinated and incomplete:

\section{...mere preparedness and response mechanisms are not enough. These must be coordinated with active mitigation and long-term recovery programs which should be set in the context of state development plans (NGA 1979:9)}

In recent times, PPRR has been criticized for not including flood information and risk assessment, these being prerequisites of prevention, and central to modern flood management (Crondstedt 2002, NFRAG 2008, Rogers 2011). Rogers (2011) suggests this can be addressed by simply extending the existing framework rather than abandoning it. This has been done in the UK, where anticipation and assessment have been added to the standard framework (HM Government 2013).

Although the PPRR framework continues to be widely used, more recent emergency management policies and mechanisms have centered on the concept of improving disaster resilience. At first, resilience appears to be a paradigm shift away from the PPRR framework. Among the changes associated with resilience is a move from simply considering disaster likelihood, to also considering consequences, corresponding with the modern riskbased approach (NRC 2012a). Related to this is the acknowledgement that regardless of the effort invested in prevention, residual risk will remain and contingency measures are needed to reduce damages (NRC 2012a, AGD 2013).

Another distinctive element of resilience is the twin concept of "shared responsibility," which expects those who live in hazardous areas to become increasingly self-reliant (COAG 2011, UNISDR 2015a). According to political discourse, people are thus transformed from being victims (vulnerable: negative) to actors in control of their own destiny (resilient: positive). This framing of resilience is politically powerful; not only does it reduce government responsibility but it aims to appeal to people's pride in being strong enough to cope with setback. However, critics observe that disaster resilience policies can sometimes disempower communities because of lack of focus on underlying causes, budget reductions, or imposition of "improvements" (Reghezza-Zitt et al. 2012, Sudmeier-Rieux 2014).

Despite these conceptual shifts, resilience and PPRR are very closely intertwined. Both appear to have their origins in a desire to increase emphasis on preventative measures (UNISDR 2015b). PPRR also frequently appears in disaster resilience definitions or text. For example, Australia's National Partnership Agreement on Natural Disaster Resilience defines resilience as "the capacity to prevent/mitigate, prepare for, respond to and recover from the impacts of disasters" (COAG 2009:Schedule A). Senior Australian bureaucrats, when discussing the establishment of new arrangements, state the following: "the foundations of this new way of thinking came largely from work within the field of organisational resilience...the aim of current EM policy is to use [the PPRR] model to work towards a more disaster resilient Australia" (Prosser and Peters 2010). Australia is not the only country where resilience and PPRR are closely connected. This also appears to be the case in the USA (e.g., DHS 2011, 2013, NRC 2012b, White House 2013) and internationally (e.g., UNISDR 2015a, United Nations 2005). In the USA, executive orders and presidential policy directives often reflect PPRR in disaster resilience definitions, with "anticipation" added and "mitigate/prevent" becoming "adapt" (Wenger 2017). In the Netherlands, PPRR takes the form of "multilevel safety," which is said to enhance resilience (Zevenbergen et al. 2013).

The apparent seamless graft of resilience onto PPRR leads to the potential error that every measure within the PPRR framework (subject to local conditions) can be said to increase resilience. This is sometimes articulated even in academic circles (NRC 2012b, Cutter et al. 2014). However, as discussed in earlier sections, theoreticians in the field of disaster resilience commonly distinguish between resilience and resistance, and between incremental and transformative approaches. In this light, reassessment of the PPRR framework and the activities it supports is overdue.

\section{METHODS}

For the purposes of this study, the standard PPRR framework was modified to address issues highlighted in the introduction (Table 1). The revised framework incorporates an "anticipate category" and restructures "prevent/mitigate" and "prepare" categories, resulting in a framework that is better able to distinguish resistance style measures and activities that are potentially more transformational. Measures such as land use change and development restrictions are in the "avoid" category, while structural resistance measures are largely covered by the "exposure reduction" category. Preparedness has been classified under the broader "accommodate" category, which comprises measures that help communities to live with flooding.

A literature review covering 105 global and national sources (China, The Netherlands, Australia, and the United States) was used to investigate interpretations of "disaster resilience." These countries were selected because all have recently experienced major flooding and undergone policy review (Wenger et al. 2013), and are thus likely to have considered disaster resilience concepts. Although the focus was on flooding, sources sometimes covered 
Table 1. The modified prevent-prepare-respond-recover (PPRR) framework used in this study. The table shows both the original PPRR framework and the revised framework categories. Activities were grouped under categories and can be found in Appendix 1.

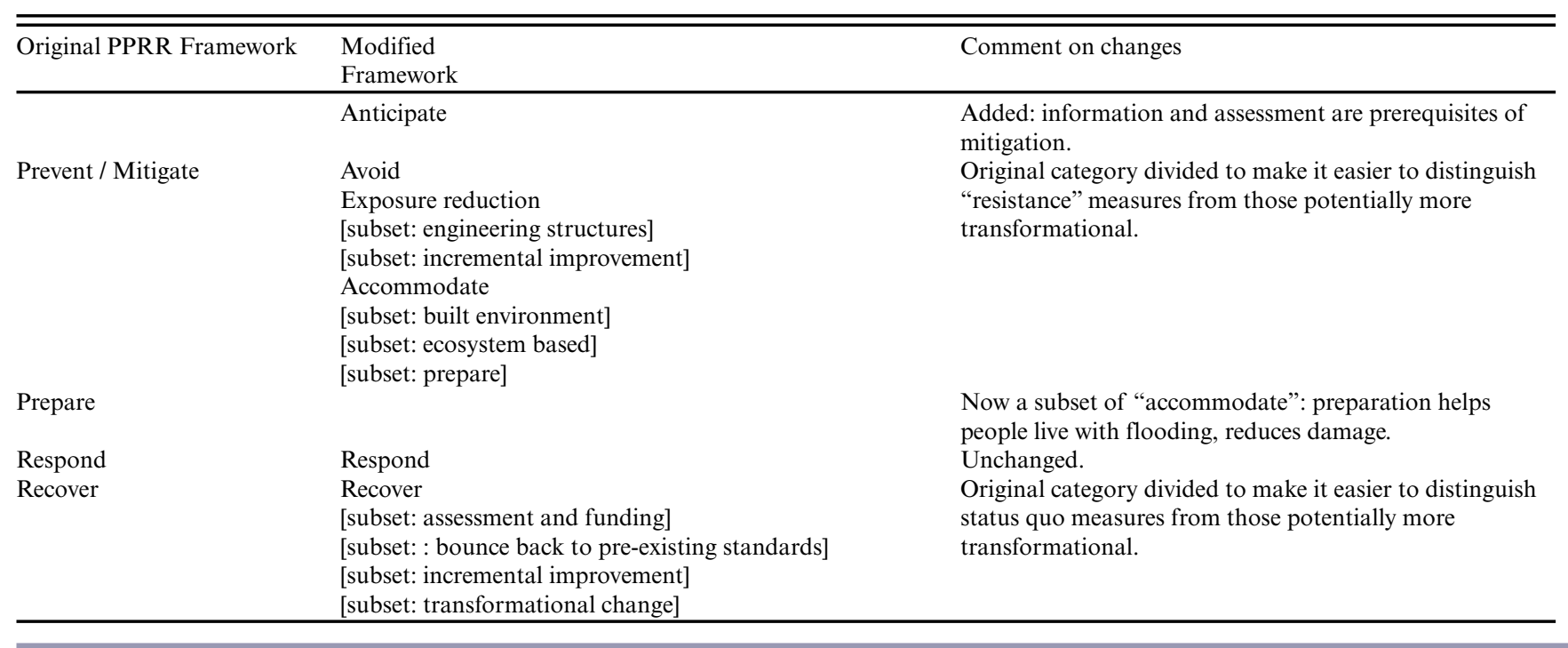

more than one hazard type and many measures are applicable across hazards. Informed by a review of theoretical concepts, case study analysis took particular note of themes relating to resistance, exposure, and transformation. The object was to determine the kinds of on-the-ground measures supported by the concept of resilience, and to identify commonalities and differences. A related goal was to explore the language used in resilience definitions and its influence on the type of measures supported.

Document selection attempted to trace the earliest appearance of disaster resilience in national disaster and flood management policy and to track it through to contemporary (2015) policy. As well as emergency management and flood management, related portfolios including climate change and infrastructure were examined. Reports by independent agencies and expert groups were checked, including the USA's National Research Council, the Dutch Deltares, Australia's Productivity Commission and Business Roundtable for Disaster Resilience, and the Chinese Academy of Sciences. Where a specific jurisdiction had experienced recent severe flooding (e.g., Hurricane Sandy in New York City, USA, Cyclones Yasi and Oswald in Queensland, Australia), subnational policies for these areas were also investigated.

For China and the Netherlands, research relied on English translations of publically available official documents. It was found that Chinese Government sources did not use the word resilience, even when involved with international resilience initiatives and Dutch Government sources have only recently started using the word. Where government documents did not use the word resilience, academic sources written by a person originating from that country and commenting on national policy were identified using a scopus search (resili* + country). This said, Dutch academic sources often have a close relationship with government agencies, e.g., have produced work for agencies; some authors identified themselves as government officials.
The literature review used a systematic approach whereby disaster resilience activities identified by sources were tabulated into the modified PPRR framework. Because there are limits to information that can be gleaned from a table, case study narratives were also prepared (detailed narratives are available at Wenger 2017). Analysis required documents to link disaster resilience to an idea or an activity. For example, a sentence might state that a measure increases resilience, or it could be discussed under a "resilience" title or subheading. Less direct links were also accepted. For example, one section of a document might link "flood mitigation" or "disaster risk reduction" measures to increased disaster resilience. Mitigation or risk reduction measures identified elsewhere in the document were therefore included, whether or not the section reiterated that their use increased resilience. Word search was used to help navigate documents and identify linkages.

\section{Data analysis methods}

For data analysis, the relative significance of each category within a country was assessed. This was expressed as the percentage of documents that associated the category with resilience (Fig. 1). This only provides a generalized overview as a document that covers one activity within a category is weighted equally against sources that identified several activities. A potential bias was that many documents examine resilience in a specific context, such as critical infrastructure, dams, and levees or land use planning, which makes it more likely for them to cover some categories than others. However, it could also be argued that if a single issue is of such importance to a country that it merits its own resilience document, this is also significant.

To determine the relative importance of resistance measures that aim to maintain status quo, as opposed to transformational adaptation measures, more detailed analysis was carried out of three indicators: exposure reduction, ecosystems based approaches, and underlying causes (the latter comprising three activities drawn from different categories). During the course of 
Fig. 1. The relative significance of framework categories for each case study. Graphs indicate the percentage of references $($ total $=\mathrm{n})$ that link at least one activity in a category to resilience. Activities associated with each category are listed in Appendix 1. Note the category "accommodate" has been divided into three subcategories to make it easier to distinguish strategies covered in the discussion.
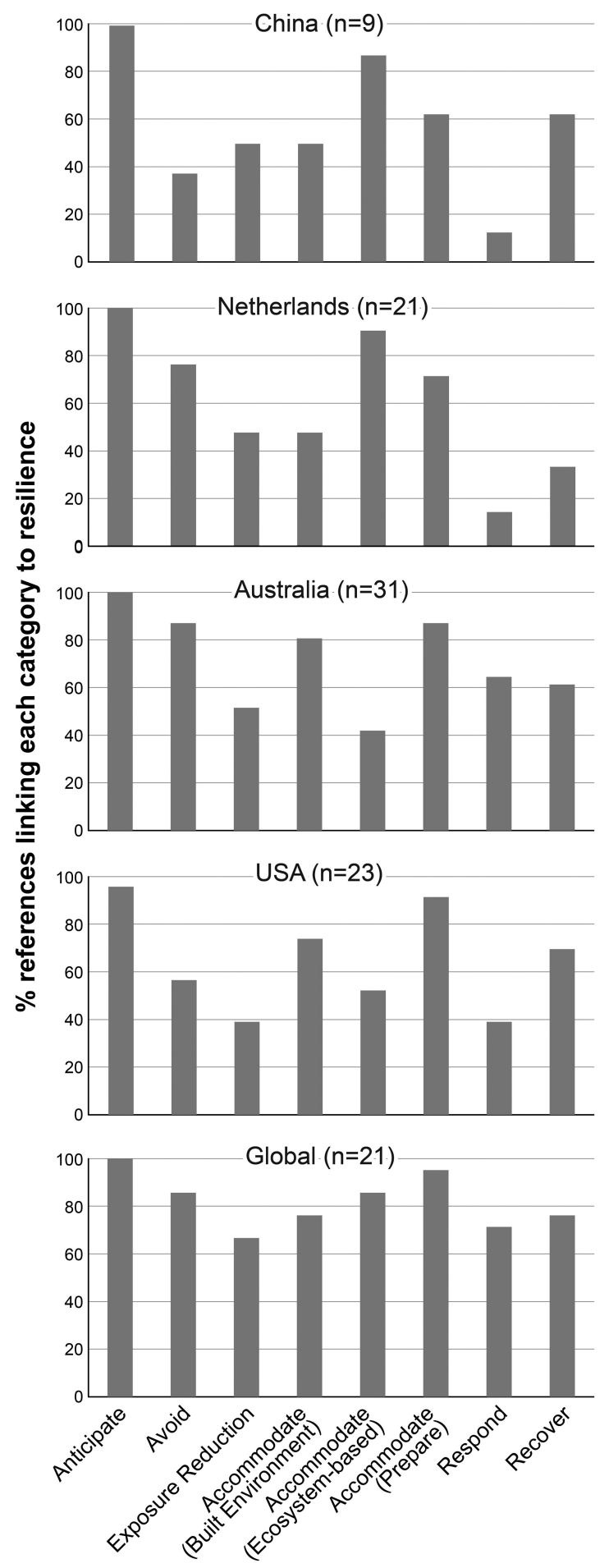

Framework categories the research, it was observed that sources dedicated significant space and discussion to some measures, but inclusion of others appeared tokenistic. Therefore, a more granular analysis was undertaken of these "indicator" categories and a weighting system was used. The rationale behind the weighting system was that the more significant the category, the more detail and depth should be provided by source documents and the higher the number of activities within the category were likely to be covered. Weighting was done by calculating the total number of activities for the relevant indicator and multiplying it by the total number of source documents in a country to arrive at a $100 \%$ saturation figure (number of possibilities). Then the actual number of sources for each activity in the country was calculated, to arrive at a saturation percentage. General trends were also checked without using the weighting system to verify they were consistent.

The exposure reduction category was used as an indicator for resistance (results: Fig. 2). This excluded the "improvement" activity, which proved ambiguous as some modifications aimed to increase resistance, while others aimed to permit more flooding. Ecosystem based approaches are strongly associated with a change in mindset and values, from control to acceptance of natural processes, and are thus illustrative of transformational adaptation (results: Fig. 3). Another indicator of transformation is the willingness to analyze and address underlying causes, rather than responding to symptoms. For this, a meld of activities was selected from different categories (results: Fig. 4).

Fig. 2. The relative importance of exposure reduction in disaster resilience interpretations. Exposure reduction comprises six activities (see Appendix 1) and is used as an indicator of the degree to which resilience interpretations are resistant. Note the subcategory, "incremental improvement" was omitted because it proved ambiguous, because some activities enabled increased flooding, and were thus not an indicator of resistance. The percentage figure is based on the number of exposure reduction activities identified by each case study reference. Percentage calculations used the following figures: (1) Actual number of activities identified by each case study source, summed. (2) Total number of possibilities $=$ total exposure reduction activities (6) $\mathrm{x}$ total source documents for each case study.

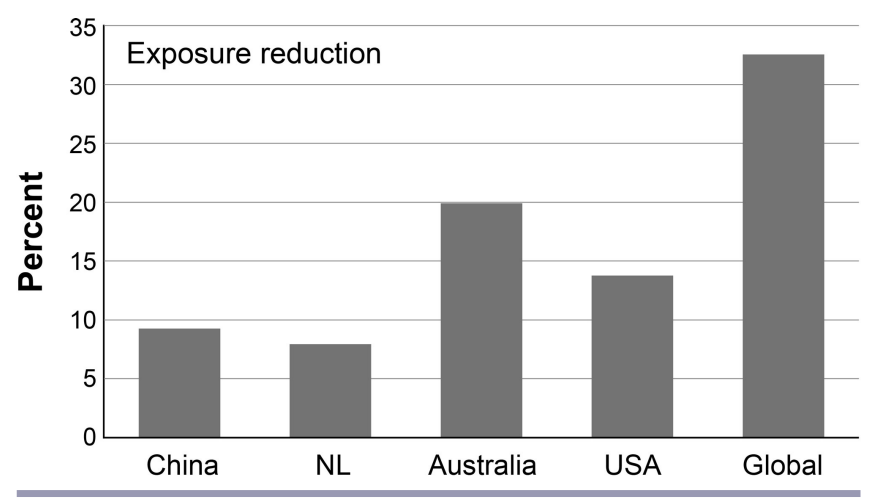

\section{Interpreting results}

Several caveats should be made when interpreting results. First, China's sample size was small (as discussed above, resilience was not a word used in English translations of official documents). 
Furthermore, this study investigates the written word and not the relative financial support provided for different measures in program budgets. Were budgetary comparison to be made, it would be important to bear in mind that different measures vary greatly in cost, and that expenditure may not, therefore, represent a true picture of how resilience is interpreted.

Fig. 3. The relative importance of ecosystem based approaches in disaster resilience interpretations. The ecosystem based subcategory comprises eight activities (see Appendix 1) and is used as an indicator of the degree to which resilience interpretations are transformational. The percentage figure is based on the number of exposure reduction activities identified by each case study reference. Percentage calculations used the following figures: (1) Actual number of activities identified by each case study source, summed. (2) Total number of possibilities $=$ total ecosystem based activities $(8) \times$ total source documents for each case study.

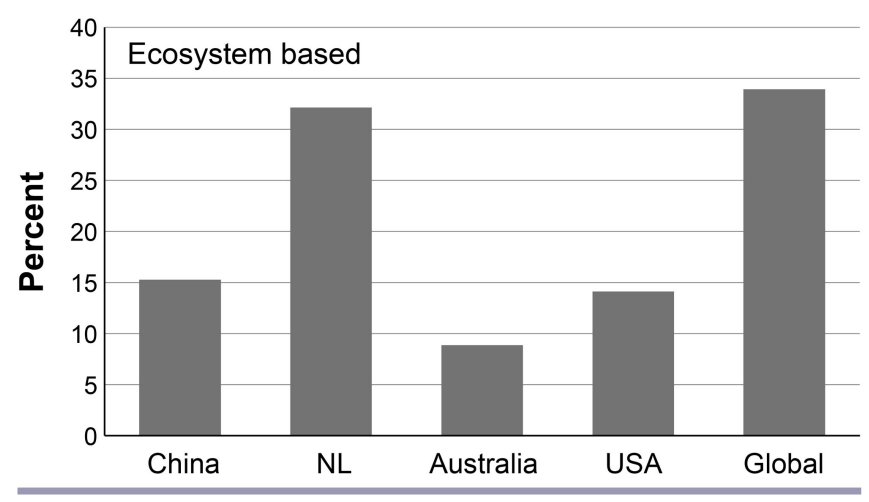

Fig. 4. The relative importance of underlying causes in disaster resilience interpretations. The ability to understand and address underlying causes is indicative of a transformational approach. It has been calculated using three activities: understanding underlying causes; climate change mitigation; and reducing the vulnerability of disadvantaged groups. Percentage calculations used the following figures: (1) Actual number of activities identified by each case study source, summed. (2) Total number of possibilities $=$ total underlying causes activities $(3) \times$ total source documents for each case study.

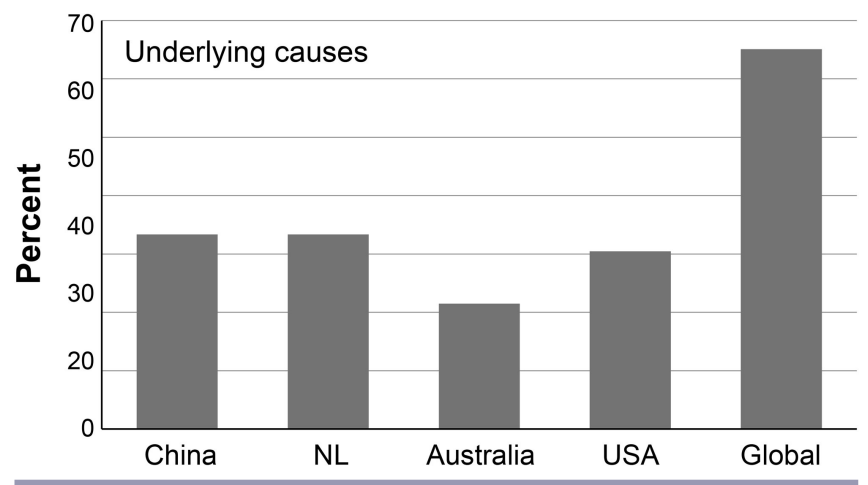

\section{RESULTS}

\section{Statistical analysis: framework categories}

A comparison of framework categories was undertaken for each case study area (Fig. 1). National case studies show high variability between categories. The Netherlands has the largest variability, with $100 \%$ of sources linking resilience to "anticipate" measures, as compared with $14 \%$ interpreting resilience in terms of "respond," a difference of 86 percentage points. The Global case study has the lowest variability. It broadly supports all categories with a difference of 33 percentage points between highest ("anticipate") and lowest ("exposure reduction"). This may reflect the need to be inclusive on the international stage to accommodate the varying needs and approaches of all countries.

Analysis indicates that all case studies strongly associate resilience with "anticipate" and "accommodate: prepare" measures. Of "accommodate: prepare" activities, Australia, the USA, and Global all exhibit strong correlation of resilience with "institutional arrangements," and Global displays by far the strongest link between resilience and "reducing vulnerability of disadvantaged groups" ( $90 \%)$. Australia has the highest score for "awareness of risks and knowledge of what to do before and during an emergency" (84\%) and "shared responsibility; selfreliance" (61\%) (Fig. 5). It also scores highly in related activities, "capacity building" (65\%), "hazard information" (77\%), and "risk assessment" (94\%), with recognition that information is a prerequisite for risk awareness and action. These findings reinforce a recent interview-based study of resilience framing by Australian flood practitioners, which found self-reliance to be a dominant theme (Aldunce et al. 2015). As suggested by the authors, this could be partly explained by neoliberalism, a link well-explored by Zebrowski (2013). However, the current study suggests greater prominence of this interpretation in Australia compared with elsewhere. This could be a consequence of the Australian Federal Government's limited constitutional role in natural resources management. With restricted power over development planning (coupled with financial responsibility for large-scale disaster damage), the promotion of "shared responsibility" is a logical policy choice.

Fig. 5. The relative importance of self-reliance in disaster resilience interpretations. This graph shows the percentage of documents within each case study that link disaster resilience to the activities "shared responsibility" and "awareness of risks / what to do in an emergency."

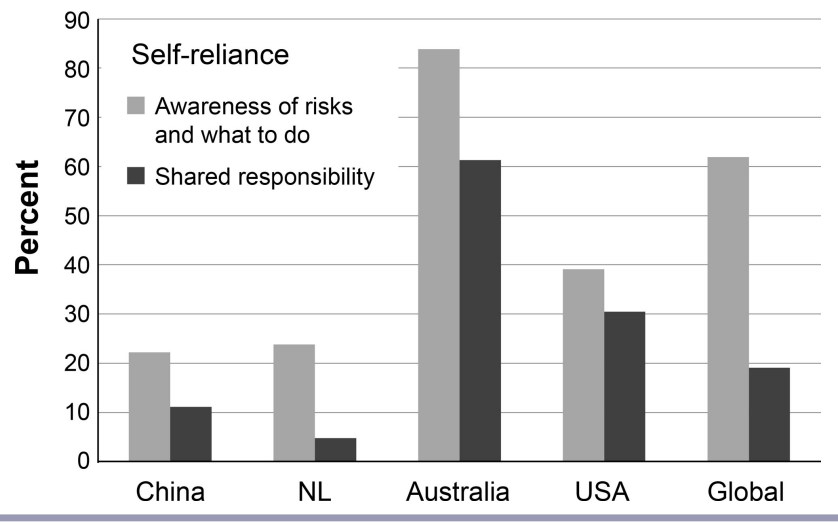


The "avoid" category has strong correlation to resilience in all case study areas except China. On the surface, avoidance of flood hazard areas appears highly adaptive. However, sources are not necessarily explicit about the degree of avoidance intended. Policy documents from the Netherlands suggest a more forward-looking approach, whereby development is restricted in some areas to permit the expansion of floodable land should it be required in the long-term future (Deltacommissie 2008, NEAA 2011). However, in other instances land use planning and zoning requirements support business as usual. Annual exceedance probability (AEP) is the probability of exceedance of a given discharge within a period of one year. For example, a discharge that has a probability of being exceeded once every 20 years ( 1 in $20 \mathrm{AEP}$ ) has a $5 \%$ probability of being exceeded in any given year $(5 \%$ AEP). Effectively, this enables continued floodplain development (Wenger 2015a). Similarly, in the USA additional development is planned for $60 \%$ of land along the Atlantic coast within a meter of sea level (GAO 2015). Regardless of construction standards imposed in these zones, ultimately, controls may prove inadequate for addressing changing flood patterns associated with global warming.

"Respond" and "recover" receive somewhat variable support and are generally less significant than "anticipate," "avoid," and "accommodate" categories. Australia and Global score highest in the "respond" category and the USA and Global are highest in "recover" (with "financing recovery," particularly through insurance, being the most significant recovery activity for all case studies). These categories are least significant in the Netherlands, perhaps because of its high level of structural protection.

\section{Resistance and transformation}

Language in operational source documents often uses words such as "withstand," "resist," or "protect." This is found in both resilience definitions and text (Wenger 2017). Some definitions include both resistance and flexibility or adaptation, although only one definition (IPCC 2014) was found that included capacity to transform.

A more detailed analysis was undertaken to compare the relative importance of resistance strategies (using "exposure reduction" as the indicator) and measures more strongly associated with transformational change, using "accommodate: ecosystem based approaches" (EBA) and a composite "underlying causes" category. The "underlying causes" category comprises "investigate / understand underlying disaster causes" ("anticipate") and two activities that address causes: "climate change mitigation" ("avoid") and "reducing vulnerability of disadvantaged groups" ("accommodate: prepare").

All case studies except Australia associate disaster resilience more strongly with "EBA" than "exposure reduction" (Fig. 1). Comparison between countries (Figs. 2, 3, and 4) reveals a similar picture. For "exposure reduction" measures (Fig. 2), flood barriers, including levees, was the activity most commonly referenced. Note that Figure 2 excludes the exposure reduction "improvement" activity, which proved ambiguous because some modifications aimed to increase resistance, while others aimed to permit more flooding. Global sources display the highest correlation of resilience with "exposure reduction," (reflecting high support for all framework categories), Australia is second highest and the Netherlands the lowest. Conversely, the Netherlands and Global score the highest in the "EBA" category and Australia the lowest. This pattern could be attributed to the long history of levee use in the Netherlands, China, and the USA, giving rise to greater evidence of levee problems in those countries than in Australia (Wenger 2015b). This suggests a potential for bias within the "EBA" category, with Australia more likely to favor activities that preserve "existing" landscape features (such as "protect / enhance natural floodways and buffers: wetlands, riparian and coastal ecosystems"), and countries such as the Netherlands likely to favor "rectification" activities (through measures such as dyke removal or relocation). To some degree this is the case. The former activity rates the highest mention among Australian sources, and the latter is highest in the Netherlands. However, even for the former, the Netherlands rates more highly than Australia.

The other indicator used to reveal transformational interpretations of resilience was "underlying causes" (Fig. 4). Comparison between case studies shows Global is highest, China, the Netherlands, and the USA are almost on a par, and Australia is lowest. That the country that associates resilience most highly with "shared responsibility" has the lowest association with "underlying causes" is noteworthy given criticism of resilience policy (see introduction).

There are nuances in the way different case studies cover underlying issues that are not obvious in the broad-scale statistical analysis. When identifying underlying causes, national sources tend to focus most heavily on underlying climate issues and sometimes on natural resource degradation. Where social issues are covered it is usually in relation to population growth. By contrast, the global sphere (which also covers climate change and natural resource condition), is concerned with complex social equity issues. Some USA sources cover social disadvantage (CNY 2013, Thomas and DeWeese 2015), perhaps as a consequence of the 2005 New Orleans disaster where linkages between disadvantage and impacts were evident (Kates et al. 2006, Tierney 2006). The Netherlands rarely covers social inequity. The few that do either deny inequity, on the basis of health, access to information, and income, or only mention it in the context of international policy. However, Wolsink (2006) makes it clear that power inequities in the Netherlands affect flood management outcomes. Australian sources often cover social inclusion to reduce vulnerability (for example, risk awareness campaigns targeting disadvantaged groups) but tend to avoid underlying issues that cause disadvantaged groups to be at greater risk.

Given that climate change is a commonly cited underlying cause, it is interesting that climate change mitigation is rarely associated with disaster resilience. This does not imply an absence of climate change mitigation policy, but is more likely to indicate policy division, with climate change portfolios addressing causes and disaster resilience addressing effects through adaptation options. Overall, results suggest the Netherlands has the most consistently transformational interpretation of disaster resilience and Australia the most resistant, while in the global arena, relatively high support is shown for all measures.

\section{DISCUSSION}

\section{Changing feedbacks}

It is evident from results that the interpretation of disaster resilience varies according to country, some being more resistant than others. However, to some extent resilience interpretations 
from all case studies support resistant measures such as flood barriers, and the use of language such as "resist" and "withstand" reinforces resistance as part of operational resilience ideology. Although flexible words such as "adapt" are often incorporated into resilience definitions, the degree of adaptation is limited so as to "maintain existing systems and structures": the pursuit of stability and status quo. Moreover, "adaptation" may be interpreted as encompassing any change, including the use of resistant measures.

It would appear, therefore, that interpretations of resilience that acknowledge the importance of exposure and instability, lack consideration at the political and operational level. As discussed, when the concept of resilience was adopted it was superimposed onto the pre-existing disaster management PPRR framework. PPRR is not discriminatory and it incorporates a comprehensive suite of possible management options for each disaster phase. The more recent Disaster Risk Reduction (DRR) approach is also associated with resilience. It is similar to PPRR except that it focuses on action taken prior to disasters (PP, rather than RR), including an emphasis on underlying social causes. DRR definitions include exposure reduction (UNISDR 2009). This encompasses development restrictions and measures such as flood barriers. The presence of pre-existing disaster management options and frameworks is likely to have colored the interpretation of resilience when it transferred to the operational domain. Instead of reassessing possible management options in the light of academic theories about the true nature of resilience, it was easier operationally to create a meld of engineering and SES interpretations. In this way, all management options continued to be available. Resilience can thus justify any activity, which limits its usefulness as a guiding concept.

Of particular concern is resilience's stated aim in many definitions to "maintain existing systems." A social-ecological resilient system is one that retains essential feedbacks and identity (Walker et al. 2004), and resilience definitions that express the ideal of maintaining existing functions, systems, and structures accurately reflect ecological and SES resilience theories. However, as many have pointed out, a resilient status quo is not necessarily desirable and may not lead to desirable adaptation pathways that will endure in the long-term (Wise et al. 2014). As discussed earlier, status quo can be maintained using resistant measures such as levees and incremental adaptation. This may suffice over the short term but can accumulate risks for the future. Resilience interpretations also need to encompass the transition from less desirable to more desirable regimes, by identifying intervention points and deliberately altering system feedbacks. This has been identified as a priority for resilience research (Miller et al. 2010, Sjöstedt 2015).

The often-cited levee paradox, (Fig. 6), or "levee effect," is a highly resilient undesirable system, whereby levees create artificially stable systems that encourage greater development of hazardous areas, and thus greater potential consequences (Smith 1998). Levees ameliorate short to medium term flood risk. However, they are unlikely to cope with "unprecedented" floods or events of a magnitude outside living experience, such as the storm that felled the oak. Such events are likely to occur more frequently because of climate change and the IPCC remarks on the "unavoidability of sea level rise in the long term even with stringent mitigation"
(IPCC 2014:366). Ultimately, relocating at-risk assets may be the only option.

The levee paradox is a feedback system supported by inadequate planning legislation and "resistant" interpretations of resilience that treat the symptoms of bad planning with structures. Levee drawbacks are widely recognized and even sources that support them also draw attention to their ecological and safety problems. The paradox thus forms an interesting transformational challenge.

At this juncture, it is important to question what is meant by "a resilient status quo": what is resilience trying to preserve? Some view this in geographic terms: people continuing to live and work in the same place, maintaining their location-based identity, including its subculture, history, and economic base (e.g., Klein et al. 2003, Campanella 2006). The locational definition is a practical unit from an emergency management point of view (McAslan 2010). According to this perspective, a city lacking resilience is unlikely to be wiped out, but it could decline following disaster, or conversely strengthen if resilient (Gunderson 2010). Taking a more institutional viewpoint, resilience could be viewed in terms of the underlying power structures it supports, which may or may not be desirable. Inequity in existing social landscapes can result in disadvantaged groups being assigned to hazardous (but affordable) locations in low quality housing that will perpetuate long-term risks. Policies to increase resilience may focus on short-term actions and recovery in preference to addressing these underlying causes (Sudmeier-Rieux 2014). Recovery efforts may discriminate between social groups and industries in a way that further entrenches disadvantage and benefits existing power structures (Vale 2014). In the results section it was seen that countries differ in their attention to underlying issues. For long-term, sustainable solutions, disaster resilience strategies need to recognize and address root causes of vulnerability. In the case of the levee paradox, the resilience aim might be the preservation of a development and economic growth paradigm, whereby as much land as possible is made available for development as cheaply as possible, including low value swampland (Burby 2006). This is where institutional feedbacks favoring levees intersect with higher level government policies that promote economic growth, employment, and affordable housing (Abel et al. 2011).

Such policies are challenged when social thresholds are breached and create discontent, such as air pollution in China, or environmental damage caused by structural mitigation in the Netherlands (Huitema 2002, PRC 2015, Rohde and Muller 2015). Change of mindset, e.g., from control floods to live with floods, underlies feedback change, motivating political will and enabling public acceptance. For a change of mindset to occur, a society may have to experience firsthand the draw backs of large-scale flood control. Merely observing the experience of other countries may not be sufficient incentive to do things differently.

One of the biggest issues invoked in debates about different adaptation options is trade-offs (IPCC 2014, Chelleri et al. 2015). Often, options that are more desirable from a long-term or ecological viewpoint are less desirable from a social perspective. For example, although flood studies might show that an area is at considerable risk of eroding coastlines, storm surge, and flooding, some occupants, including the elderly, may not be able 
Fig. 6. The levee paradox. This diagram, building on Smith's (1998) description, illustrates system incentives and feedbacks that encourage levee construction and risk accumulation. External funding is available, subject to benefit cost analysis (BCA), which limits the design protection level. Nevertheless, it generates a perception of safety that encourages continuing development. Meanwhile other communities, perhaps in the same rate-paying local government area, observe benefits flowing to the levee-protected community and pressure mounts for similar levee protection. Additional development (associated with increased runoff) and reduced flood storage effectively reduce the protection afforded by the initial levee design. The levee overtops in a major flood, and pressure mounts for incremental increases in levee height or extent. An arrow's polarity is positive when an increase/decrease of a cause has a corresponding increase/decrease on an effect. When polarity is negative, an increase/decrease of a cause has a decrease/increase in the effect (Newell and Wasson 2002).

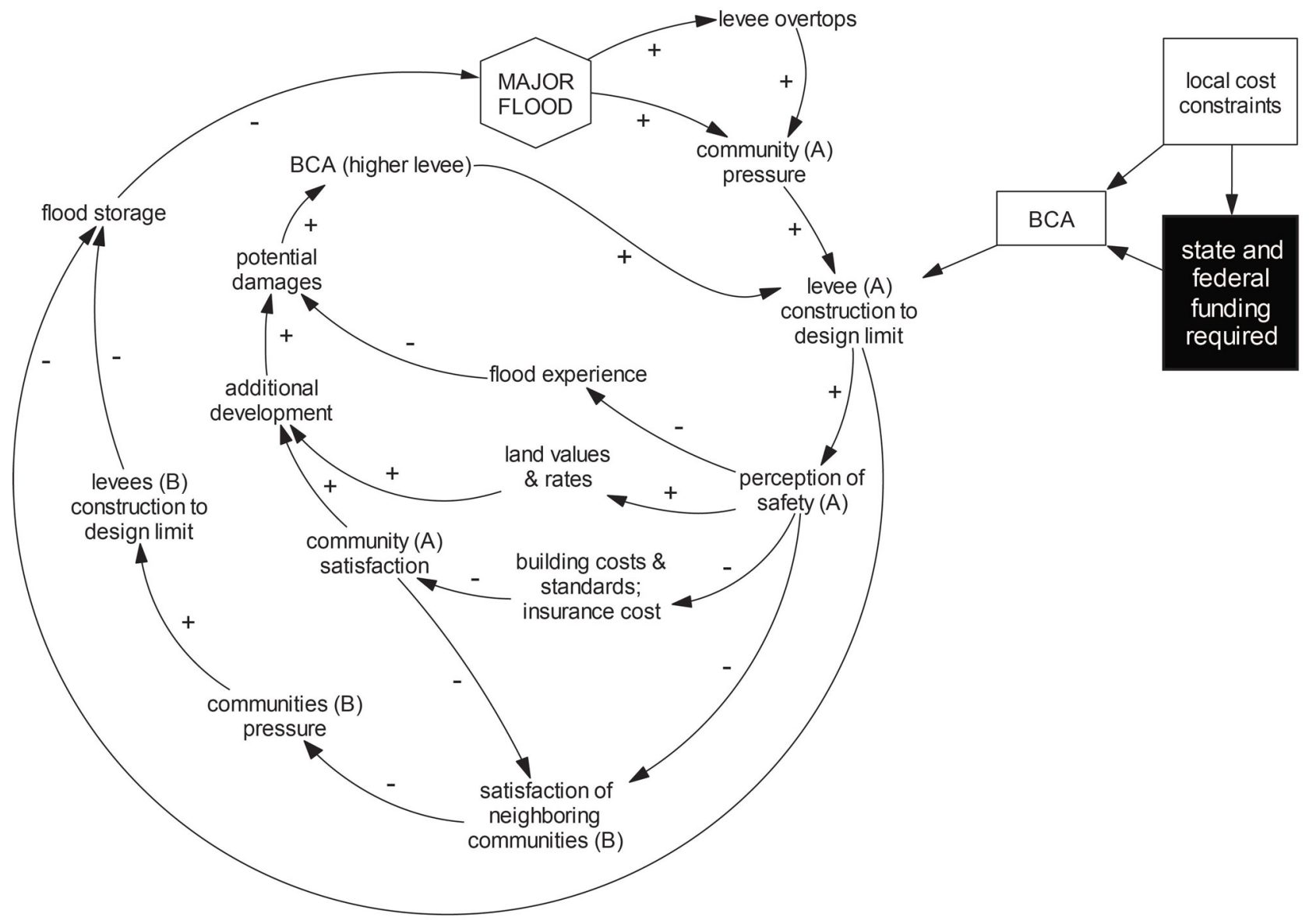

to afford the costs of retrofitting, and the relocation of long-term residents might cause great grief. An asset may still have many years before it needs replacing or rebuilding elsewhere. A socially responsible response might provide for both short-term safety and allow time and incentives for long-term transformational adaptation to take place.

Figure 7 looks at options to alter levee paradox feedbacks. In this example, levees are used as a temporary solution to enable adjustment to take place. Time-limited protection coupled with funding conditions create incentives to either remove susceptible development from the floodplain or replace it with development types and designs that can accommodate long-term changes in flood risk. Theoretically, this would alter feedbacks, reducing exposure and impacts and lowering the imperative for protection. Although not identical (in that levee decommission was not planned), levees have been used to assist adjustment to higher flood risk by allowing time for it to occur (Western and Kellett 2014). There is also a precedent for time-limited approval of other types of hydrological structure, including dams (Russo 2000, Pittock and Hartmann 2011).

Preplanned decommission may be unpopular. However, it would provide added incentive for change and would prevent long-term damage to hydrological systems. It would also reinforce the idea that hazard risks are no longer stationary because of climate change and that levees are not a long-term solution. Another common issue affecting levee safety is lack of maintenance by local governments because of cost or complacency, and consequent unreliability as levees age. Levee decommission could be planned to occur before significant maintenance issues are anticipated. 
Fig. 7. Changing feedbacks. Altered system feedbacks may lead to transformational change and greater long-term resilience. External funding provides transitional protection (Pathway A), allowing communities both time and incentives to adjust voluntarily. Incentives such as inbuilt requirements for levee decommission remove the perception of permanent protection. Existing residents may remain. However, in return for temporary protection, governments may require that buildings be modified or apply preferential purchase agreements at (indexed) prelevee prices to implement land use change over the longer term. While retrofitting or rebuilding existing structures is encouraged, a temporary moratorium on additional development prevents perverse incentives for development intensification within levee-protected areas. By the time the levee is decommissioned (Pathway B), the high-risk area has undergone changes that enable better accommodation of flooding and reduced impacts. Ongoing exposure engenders flood experience and motivates continual improvement.

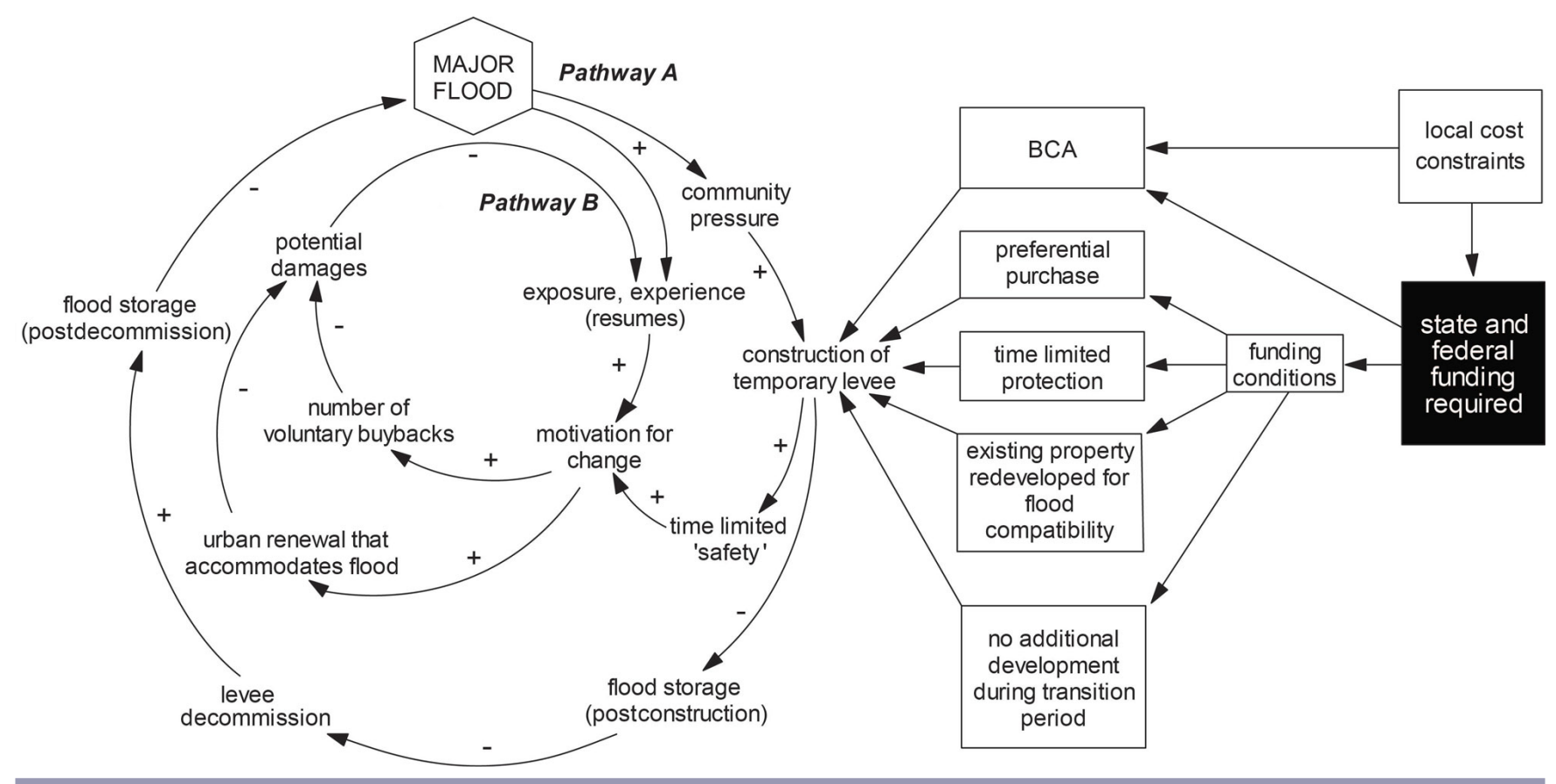

The levee paradox has other potential intervention points. Unless raised haphazardly with bulldozers as a flood approaches, levee building is an expensive exercise involving flood studies, options assessment, consultation, cost-benefit analysis, assessment of offsite impacts, design, and construction. It is often beyond the financial means of local governments and usually requires funding from higher levels of government. In Gympie, Queensland, the more transformational option of removing development from the floodplain only gained support once the levee option, which would have attracted state government funding, was abandoned (Crisafulli 2014b). The very willingness of higher levels of government to fund large-scale engineering projects can prevent the implementation of sustainable, long-term solutions.

\section{Shared responsibility and climate change adaptation}

Case studies exhibit a strong link between disaster resilience and preparedness, including shared responsibility and self-reliance. This is a sound climate change strategy, as recent flood events illustrate that emergency services are easily overcome in extreme events (Pitt 2007, Comrie 2011, QFCI 2011).

However, shared responsibility equates to responsibility for residual risk and can mask underlying causes such as inadequate development policies. Once flood risk information is made available, the onus is on individuals to accept the risks they live with and to act accordingly. This is based on the premise that people have a choice, which for financial and employment reasons might not be the case (UNISDR 2015b). Shared responsibility on a community level usually involves local governments taking responsibility for risk management. However, higher levels of government may not devolve the power or provide the necessary legal backing for local governments to impose adequate planning controls. Higher level development interests may override local safety concerns and participatory processes may only provide an illusion of choice. In Australia, for example, sea level benchmarks have been abandoned and state government legislation and policy fail to support local governments wishing to prevent unsafe development (Gordon and Pang 2004, QFCI 2012, Sellers and Mooney 2012, SCCG 2012, Kellett et al. 2014, Stokes and Faulkner 2014).

\section{If not resilience, then what?}

Although the conclusion of this paper is that resilience is too malleable a concept to guide disaster management, the convergence between resilience and adaptation theory offers great potential for reassessing operational frameworks. These research fields concur on the undesirability of structural options, such as levees. Although adaptation theorists view them as maladaptive, resilience theorists suggest that stability-inducing interventions prevent long-term resilience.

SES resilience theory could be usefully applied to amend existing emergency management frameworks, so they distinguish between 
resistant and accommodating management options. The amended framework developed for this paper offers a starting point but needs further refinement, the current work being constrained by the level of detail offered by source documents. For example, the intent behind activities such as avoidance and construction standards could be made clearer (whether to enable continuing development in hazardous areas or to preserve floodable landscapes for the future). A more discriminating framework could help emergency managers and development planners to better negotiate pathways that are adaptive in the long term. Echoing the findings of Klein et al. (2003), it is suggested that negotiating adaptive pathways would be a better objective for disaster management than resilience.

\section{CONCLUSION}

Many theorists argue that resilience is best conceptualized as a measurable property and much effort goes into developing resilience indicators. Others prefer to see resilience as a process characterized by adaptive capacity, whereby systems are modified to ever-changing circumstances. As such, resilience cannot have an end-point. But few study whether disaster resilience policies are likely to lead to long-term adaptive outcomes. Once "resilience" is operationalized, outcomes cannot be brushed aside. It is vital to assess whether disaster resilience strategies are likely to lead to desirable outcomes in terms of long-term climate change threats and the sustainability of natural resource systems upon which human societies depend. This requires examination of how resilience theories translate into policy and activities.

Politically, resilience is useful because it is sufficiently ambiguous to support a wide variety of management policies: in Australia, it is used to support structural approaches and the continued development of floodplains, while in the Netherlands it is used to support floodable landscapes. This lack of consistency may be due to resilience theories having been superimposed upon the PPRR framework without much analysis, to the extent that they are sometimes expressed in almost identical terms. Assessment of the PPRR framework in the light of resilience theory suggests there is a commonly held view that all mitigation or disaster risk reduction activities lead to increased resilience, despite many of these being resistance-style measures. Yet some suggest resilience entails increasing the ability to cope with instability through acceptance, not elimination of exposure. The PPRR framework fails to distinguish between measures conducive to long-term resilience and maladaptive options that are less likely to achieve this.

In this paper, it is argued that disaster resilience policies need to be more discriminatory in the activities they support or they will not lead to adaptive outcomes able to cope with large-scale climate change events. Emergency management frameworks need to be critically assessed and revised and measures reviewed to determine how they can contribute to long-term desirable outcomes. Although resilience theories have contributed to analysis and theoretical debate among researchers, practitioners would do better to focus on adaptation and the ultimate disaster management objective should the ability to negotiate a sustainable adaptation pathway. As in Aesop's tale, those who live at the water's edge cannot afford to be rigid but need to be able to accommodate the power and abundance of floodwater and transform it into advantage. Conversely, the pathways likely to lead to maladaptive outcomes, such as ongoing floodplain development and financing protective structures that enable this development should be discouraged. Although easy to state, this requires strong political leadership. It may be that only the occurrence of a calamitous event is able to prompt such a deep and widespread questioning of existing policies and the values on which they rest.

Responses to this article can be read online at: http://www.ecologyandsociety.org/issues/responses. $\mathrm{php} / 9491$

\section{Acknowledgments:}

This research was supported by the Commonwealth of Australia through its Australian Postgraduate Award program and the Bushfire and Natural Hazards Cooperative Research Centre program. I especially wish to thank Jamie Pittock, Steve Dovers, Katherine Daniell, and Michael Eburn for reviewing a draft of this paper. Thanks also to Clive Hilliker for graphics assistance; to Xuemei Bai for discussing the difficulties of translating "resilience" into Chinese, and to Lorrae Van Kerkhoff for feedback on methodology.

\section{LITERATURE CITED}

Abel, N., R. Gorddard, B. Harman, A. Leitch, J. Langridge, A. Ryan, and S. Heyenga. 2011. Sea level rise, coastal development and planned retreat: analytical framework, governance principles and an Australian case study. Environmental Science and Policy 14(3):279-288. http://dx.doi.org/10.1016/j.envsci.2010.12.002

Adger, W. N., N. W. Arnella, and E. L. Tompkins. 2005. Successful adaptation to climate change across scales. Global Environmental Change 15(2):77-86. http://dx.doi.org/10.1016/j.gloenvcha.2004.12.005

Aldunce, P., R. Beilin, M. Howden, and J. Handmer. 2015. Resilience for disaster risk management in a changing climate: practitioners' frames and practices. Global Environmental Change 30:1-11. http://dx.doi.org/10.1016/j.gloenvcha.2014.10.010

Alexander, D. E. 2013. Resilience and disaster risk reduction: an etymological journey. Natural Hazards and Earth System Sciences 13:2707-2716. http://dx.doi.org/10.5194/nhess-13-2707-2013

Attorney General's Department (AGD). 2013. Managing the floodplain: a guide to best practice in flood risk management in Australia. Australian Emergency Management Institute, AGD, Canberra, Australia.

Baan, P. J. A., and F. Klijn. 2004. Flood risk perception and implications for flood risk management in the Netherlands. International Journal of River Basin Management 2(2):113-122. http://dx.doi.org/10.1080/15715124.2004.9635226

Barnett, J. 2001. Adapting to climate change in Pacific Island Countries: the problem of uncertainty. World Development 29 (6):977-993. http://dx.doi.org/10.1016/S0305-750X(01)00022-5

Barnett, J., and S. O'Neill. 2010. Maladaptation. Global Environmental Change 20(2):211-213. http://dx.doi.org/10.1016/ j.gloenvcha.2009.11.004 
Bodin, P., and B. Wiman. 2004. Resilience and other stability concepts in ecology: notes on their origin, validity and usefulness. The ESS Bulletin 2:33-43.

Bohensky, E. L., and A. M. Leitch. 2014. Framing the flood: a media analysis of themes of resilience in the 2011 Brisbane flood. Regional Environmental Change 14(2):475-488. http://dx.doi. org/10.1007/s10113-013-0438-2

Burby, R. J. 2006. Hurricane Katrina and the paradoxes of government disaster policy: bringing about wise governmental decisions for hazardous areas. Annals of the American Academy of Political and Social Science 604:171-191. http://dx.doi. org/10.1177/0002716205284676

Campanella, T. J. 2006. Urban resilience and the recovery of New Orleans. Journal of the American Planning Association 72 (2):141-146. http://dx.doi.org/10.1080/01944360608976734

Carpenter, S., B. Walker, J. M. Anderies, and N. Abel. 2001. From metaphor to measurement: resilience of what to what? Ecosystems 4(8):765-781. http://dx.doi.org/10.1007/s10021-001-0045-9

Chelleri, L., and M. Olazabal, editors. 2012. Multidisciplinary perspectives on urban resilience. $\mathrm{BC} 3$, Basque Centre for Climate Change, Bilbao, Spain.

Chelleri, L., J. J. Waters, M. Olazabal, and G. Minucci. 2015. Resilience trade-offs: addressing multiple scales and temporal aspects of urban resilience. Environment and Urbanization 27 (1):181-198. http://dx.doi.org/10.1177/0956247814550780

City of New York (CNY). 2013. PlaN YC: a stronger, more resilient New York. City of New York, New York, USA. [online] URL: http://s-media.nyc.gov/agencies/sirr/SIRR singles Lo res.pdf

Comrie, N. 2011. Review of the 2010-11 flood warnings and response: final report. State Government of Victoria, Melbourne, Australia.

Council of Australian Governments (COAG). 2009. National partnership agreement on natural disaster resilience. Council of Australian Governments Standing Council for Federal Financial Relations, Canberra, Australia. [online] URL: http://www. federalfinancialrelations.gov.au/content/npa/environment/nationalpartnership/past/natural_disaster_resilience_national_partnership. pdf

Council of Australian Governments (COAG). 2011. National strategy for disaster resilience: building our nation's resilience to disasters. Council of Australian Governments, Canberra, Australia.

Crisafulli, D. 2014a. Maryborough CBD to be more flood resilient: media release. Minister Crisafulli, Queensland Government Department of Local Government, Community Recovery and Resilience, Brisbane, Australia. [online] URL: http://statements. qld.gov.au/Statement/2014/6/18/maryborough-cbd-to-be-more-flood$\underline{\text { resilient }}$

Crisafulli, D. 2014b. Options open for Gympie flood protection: media release. Minister Crisafulli, Queensland Government Department of Local Government, Community Recovery and Resilience, Brisbane, Australia. [online] URL: http://statements. qld.gov.au/Statement/2014/3/26/options-open-for-gympie-floodprotection
Crondstedt, M. 2002. Prevention, preparedness, response, recovery - an outdated concept? Australian Journal of Emergency Management 17(2):10-13.

Cutter, S. L., K. D. Ash, and C. T. Emrich. 2014. The geographies of community disaster resilience. Global Environmental Change 29:65-77. http://dx.doi.org/10.1016/j.gloenvcha.2014.08.005

de Bruijn, K. M. 2004. Resilience and flood risk management. Water Policy 6:53-66.

Deltacommissie. 2008. Working together with water: a living land builds for its future. Findings of the Deltacommissie 2008. Deltacommissie, The Hague, The Netherlands. [online] URL: http://www.deltacommissie.com/doc/deltareport full.pdf

Department of Homeland Security (DHS). 2011. National preparedness goal. U.S. Department of Homeland Security, Washington, D.C., USA. [online] URL: https://www.fema.gov/ pdf/prepared/npg.pdf

Department of Homeland Security (DHS). 2013. NIPP 2013: Partnering for critical infrastructure security and resilience. U.S. Department of Homeland Security, Washington, D.C., USA. [online] URL: http://www.dhs.gov/sites/default/files/publications/ NIPP $\% 202013$ Partnering $\% 20$ for $\% 20$ Critical $\% 20$ Infrastructure $\%$ 20Security $\% 20$ and $\% 20$ Resilience 508 0.pdf

Elmqvist, T. 2014. Urban resilience thinking. Solutions 5(5):26-30. [online] URL: http://www.thesolutionsjournal.org/node/237196

Engel, K., G. Frerks, L. Velotti, J. Warner, and B. Weijs. 2014. Flood disaster subcultures in The Netherlands: the parishes of Borgharen and Itteren. Natural Hazards 73(2):859-882. http://dx. doi.org/10.1007/s11069-014-1116-5

Folke, C. 2006. Resilience: the emergence of a perspective for social-ecological systems analyses. Global Environmental Change 16(3):253-267. http://dx.doi.org/10.1016/j.gloenvcha.2006.04.002

Folke, C., S. R. Carpenter, B. Walker, M. Scheffer, T. Chapin, and J. Rockstöm. 2010. Resilience thinking: integrating resilience, adaptability and transformability. Ecology and Society 15(4):20. http://dx.doi.org/10.5751/ES-03610-150420

Gallopín, G. C. 2006. Linkages between vulnerability, resilience, and adaptive capacity. Global Environmental Change 16:293-303. doi:10.1016/j.gloenvcha.2006.02.004 http://dx.doi.org/10.1016/j. gloenvcha.2006.02.004

Gordon, A., and J. Pang. 2004. Is there any merit in floodplain management? Floodplain Management Authorities of NSW 44th Annual Conference 11-14 May, Coffs Harbour, Australia. [online] URL: https://web.archive.org/web/20160331102718/http://floods. org.au/wp-content/uploads/Pang-Jennifer.pdf

Government Accountability Office (GAO). 2015. Hurricane Sandy: an investment strategy could help the federal government enhance national resilience for future disasters: report to congressional requesters July 2015. United States Government Accountability Office, Washington, D.C., USA. [online] URL: http://www.gao.gov/assets/680/671796.pdf

Gunderson, L. 2010. Ecological and human community resilience in response to natural disasters. Ecology and Society 15(2):18. http://dx.doi.org/10.5751/ES-03381-150218 
Handmer, J. W., and S. R. Dovers. 1996. A typology of resilience: rethinking institutions for sustainable development. Organization \& Environment 9(4):482-511. http://dx.doi.org/10.1177/108602669600900403

HM Government. 2013. Emergency response and recovery: non statutory guidance accompanying the Civil Contingencies Act 2004. Cabinet Office, London, UK. [online] URL: https://www.gov.uk/ government/uploads/system/uploads/attachment data/file/253488/ Emergency_Response_and_Recovery_5th_edition_October_2013. pdf

Holling, C. S. 1973. Resilience and stability of ecological systems. Annual Review of Ecology and Systematics 4:1-23. http://dx.doi. org/10.1146/annurev.es.04.110173.000245

Huitema, D. 2002. Regge River Basin: case study 2 of the EUWARENESS research project. University of Twente, Enschede, The Netherlands. [online] URL: http://www. euwareness.n1/results/Ned-2-kaft.pdf

Interagency Levee Policy Review Committee (ILPRC). 2006. The national levee challenge: levees and the FEMA Flood Map Modernization Initiative. Interagency Levee Policy Review Committee, Washington, D.C., USA.

Intergovernmental Panel on Climate Change (IPCC). 2012. Managing the risks of extreme events and disasters to advance climate change adaptation. A special report of Working Groups I and II of the Intergovernmental Panel on Climate Change. Cambridge University Press, Cambridge, UK.

Intergovernmental Panel on Climate Change (IPCC). 2014. Climate change 2014: impacts, adaptation, and vulnerability. Parts A and B. Contribution of Working Group II to the Fifth Assessment Report of the Intergovernmental Panel on Climate Change. Cambridge University Press, Cambridge, UK.

Kates, R. W., C. E. Colten, S. Laska, and S. P. Leatherman. 2006. Reconstruction of New Orleans after Hurricane Katrina: a research perspective. Proceedings of the National Academy of Sciences 103(40):14653-14660. http://dx.doi.org/10.1073/pnas.0605726103

Kellett, J., J. Balston, and M. Western. 2014. Sea-level rise and planning: retrospect and prospect. Australian Planner 51 (3):203-211. http://dx.doi.org/10.1080/07293682.2013.808681

Keogh, D. U., A. Apan, S. Mushtaq, D. King, and M. Thomas. 2011. Resilience, vulnerability and adaptive capacity of an inland rural town prone to flooding: a climate change adaptation case study of Charleville, Queensland, Australia. Natural Hazards 59 (2):699-723. doi:10.1007/s11069-011-9791-y http://dx.doi.org/10.1007/ s11069-011-9791-y

Klein, R. J. T., R. J. Nicholls, and F. Thomalla. 2003. Resilience to natural hazards: How useful is this concept? Global Environmental Change Part B: Environmental Hazards 5:35-45. http://dx.doi.org/10.1016/j.hazards.2004.02.001

Liao, K. 2012. A theory on urban resilience to floods - a basis for alternative planning practices. Ecology and Society 17(4):48. http://dx.doi.org/10.5751/ES-05231-170448

London Regional Resilience Forum(LRRF). 2006. Looking back, moving forward: the multi-agency debrief: lessons identified and progress since the terrorist events of 7 July 2005. LRRF,
Government Office for London, UK. [online] URL: http://news. bbc.co.uk/2/shared/bsp/hi/pdfs/23 0906 _lrrfreport.pdf

Manyena, S. B., G. O’Brien, P. O'Keefe, and J. Rose. 2011. Disaster resilience: a bounce back or bounce forward ability? Local Environment: The International Journal of Justice and Sustainability 16(5):417-424. http://dx.doi.org/10.1080/13549839.2011 .583049

Matyas, D., and M. Pelling. 2015. Positioning resilience for 2015: the role of resistance, incremental adjustment and transformation in disaster risk management policy. Disasters 39:S1-S18. http:// dx.doi.org/10.1111/disa.12107

McAslan, A. 2010. Community resilience: understanding the concept and its application. A discussion paper. Torrens Resilience Institute, Adelaide, Australia. [online] URL: http://

$\underline{\text { sustainablecommunitiessa.files.wordpress.com/2011/06/community- }}$ resilience-from-torrens-institute.pdf

Mileti, D. S. 1999. Disasters by design. Joseph Henry Press, Washington, D.C., USA.

Miller, F., H. Osbahr, E. Boyd, F. Thomalla, S. Bharwani, G. Ziervogel, B. Walker, J. Birkmann, S. van der Leeuw, J. Rockström, J. Hinkel, T. Downing, C. Folke, and D. Nelson. 2010. Resilience and vulnerability: complementary or conflicting concepts? Ecology and Society 15(3):11. http://dx.doi.org/10.5751/ ES-03378-150311

National Flood Risk Advisory Group (NFRAG). 2008. Flood risk management in Australia: the National Flood Risk Advisory Group introduces and discusses the national flood risk management guideline. Australian Journal of Emergency Management 23(4):21-27.

National Governors' Association (NGA). 1979. Comprehensive emergency management: a governor's guide. U.S. National Governors' Association, Center for Policy Research, Washington, D.C., USA.

National Research Council (NRC). 2012a. Dam and levee safety and community resilience: a vision for future practice. National Research Council Committee on Integrating Dam and Levee Safety and Community Resilience. NRC, Washington, D.C., USA.

National Research Council (NRC). 2012b. Disaster resilience: $a$ national imperative. NRC, Washington, D.C., USA.

Netherlands Environmental Assessment Agency (NEAA). 2011. Climate Adaptation in the Dutch Delta. Strategic options for a climate-proof development of the Netherlands. NEAA, The Hague, The Netherlands.

Newell, B., and R. Wasson. 2002. Social system vs solar system: why policy makers need history: UNESCO Document SC. 2002/ WS/53. Pages 3-17 in S. Castelein and A. Otte, editors. Conflict and cooperation related to international water resources: historical perspectives. UNESCO, Grenoble, France.

Norris, F. H., S. P. Stevens, B. Pfefferbaum, K. F. Wyche, and R. L. Pfefferbaum. 2008. Community resilience as a metaphor, theory, set of capacities, and strategy for disaster readiness. American Journal of Community Psychology 41(1-2):127-150. http://dx.doi.org/10.1007/s10464-007-9156-6 
People's Republic of China (PRC). 2015. Enhanced actions on climate change: China's intended nationally determined contributions. Department of Climate Change, National Development and Reform Commission, People's Republic of China, Beijing.

Pitt, M. 2007. Learning lessons from the 2007 floods: interim report. Cabinet Office, London, UK. [online] URL: http://webarchive. nationalarchives.gov.uk/20100807034701/http:/archive.cabinetoffice. gov.uk/pittreview/ /media/assets/www.cabinetoffice.gov.uk/ flooding review/flood report lowres $\% 20$ pdf.pdf

Pittock, J., and J. Hartmann. 2011. Taking a second look: climate change, periodic relicensing and better management of old dams. Marine and Freshwater Research 62(3):312-320. http://dx.doi. org/10.1071/MF09302

Prosser, B., and C. Peters. 2010. Directions in disaster resilience policy. Australian Journal of Emergency Management 25(3):8-11.

Queensland Floods Commission of Inquiry (QFCI). 2011. Queensland Floods Commission of Inquiry: interim report. QFCI, Brisbane, Australia.

Queensland Floods Commission of Inquiry (QFCI). 2012. Queensland Floods Commission of Inquiry: final report. QFCI, Brisbane, Australia.

Queensland Reconstruction Authority (QRA). 2012. Planning for stronger, more resilient floodplains: Part 2 - measures to support floodplain management in future planning schemes. The State of Queensland, QRA, Brisbane, Australia.

Reghezza-Zitt, M., S. Rufat, G. Djament-Tran, A. Le Blanc, and S. Lhomme. 2012. What resilience is not: uses and abuses. Cybergeo: European Journal of Geography, Environment, Nature, Landscape 621:1-23. http://dx.doi.org/10.4000/cybergeo.25554

Rogers, P. 2011. Development of resilient Australia: enhancing the PPRR approach with anticipation, assessment and registration of risks. Australian Journal of Emergency Management 26(1):54-58.

Rohde, R. A., and R. A. Muller. 2015. Air pollution in China: mapping of concentrations and sources. PLoS ONE 10(8): e0135749. http://dx.doi.org/10.1371/journal.pone.0135749

Russo, T. N. 2000. U.S. Federal Energy Regulatory Commission. Contributing paper prepared for Thematic Review IV.5: operation, monitoring and decommissioning of dams. World Commission on Dams, Cape Town, South Africa. [online] URL: http://rca.alaska. gov/RCAWeb/Documents/Hydroelectric/FERC.pdf

Sellers, E., and A. Mooney. 2012. So just how exceptional is Fairfield? Contesting the 100 year ARI plus 0.5 metreflood planning level. 2012 Floodplain Management Association National Conference, 21st - 24th February, Batemans Bay, Australia. [online] URL: http://www.floodplainconference.com/papers2012/ Erin $\% 20$ Sellers $\% 20$ Full $\% 20$ Paper.pdf

Sjöstedt, M. 2015. Resilience revisited: taking institutional theory seriously. Ecology and Society 20(4):23. http://dx.doi.org/10.5751/ ES-08034-200423

Smith, D. I. 1998. Water in Australia: resources and management. Oxford University Press, Melbourne, Singapore.
Stokes, A., and S. Faulkner. 2014. Submission 18: productivity commission: public inquiry into natural disaster funding. National Sea Change Taskforce Inc., Williamstown, Australia. [online] URL: http://www.pc.gov.au/inquiries/completed/disaster-funding/ submissions/submissions-test/submission-counter/sub018-disasterfunding.pdf

Sudmeier-Rieux, K. I. 2014. Resilience - an emerging paradigm of danger or of hope? Disaster Prevention and Management 23 (1):67-80. http://dx.doi.org/10.1108/DPM-12-2012-0143

Sydney Coastal Councils Group (SCCG). 2012. NSW sea level rise policy statement, coastal protection amendment bill 2012, NSW Coastal Reforms. Sydney Coastal Councils Group. Coastal Currents Spring:3-4.

Thomas, J., and J. DeWeese. 2015. Reimagining New Orleans postKatrina: a case study in using disaster recovery funds to rebuild more resiliently. Georgetown Climate Center, Washington, D.C., USA.

Tierney, K. 2006. Social inequality, hazards, and disasters. Pages 109-128 in R. J. Daniels, D. F. Kettl, and H. Kunreuther, editors. On risk and disaster: lessons from Hurricane Katrina. University of Pennsylvania Press, Philadelphia, Pennsylvania, USA. http:// dx.doi.org/10.9783/9780812205473.109

Tockner, K., S. E. Bunn, C. Gordon, R. J. Naiman, G. P. Quinn, and J. A. Stanford. 2008. Flood plains: critically threatened ecosystems. Pages 45-62 in N. V. C. Polunin, editor. Aquatic ecosystems: trends and global prospects. Cambridge University Press, Cambridge, UK. http://dx.doi.org/10.1017/ CBO9780511751790.006

Torry, W. I. 1979. Intelligence, resilience and change in complex social systems: famine management in India. Mass Emergencies 2:71-85.

United Nations. 2005. Report of the World Conference on Disaster Reduction. U.N., Kobe, Hyogo, Japan. [online] URL: https:// www.unisdr.org/2005/wcdr/intergover/official-doc/L-docs/Finalreport-conference.pdf

United Nations Inter-Agency Secretariat of the International Strategy for Disaster Reduction (UNISDR). 2005. Hyogo framework for action 2005-2015: building the resilience of nations and communities to disasters. UNISDR, Geneva, Switzerland. [online] URL: http://www.unisdr.org/files/1037 hyogoframeworkforactionenglish.pdf

United Nations Inter-Agency Secretariat of the International Strategy for Disaster Reduction (UNISDR). 2009. Terminology on Disaster Risk Reduction. United Nations International Strategy for Disaster Risk Reduction. UNISDR, Geneva, Switzerland.

United Nations Inter-Agency Secretariat of the International Strategy for Disaster Reduction (UNISDR). 2015a. Sendai framework for disaster risk reduction 2015-2030. UNISDR, Geneva, Switzerland.

United Nations Inter-Agency Secretariat of the International Strategy for Disaster Reduction (UNISDR). 2015b. The global assessment report on disaster risk reduction. Making development sustainable: the future of disaster risk management. UNISDR, Geneva, Switzerland. 
U.S. Army Corps of Engineers (USACE). 2013. Coastal risk reduction and resilience. Directorate of Civil Works, U.S. Army Corps of Engineers, Washington, D.C., USA.

Vale, L. J. 2014. The politics of resilient cities: whose resilience and whose city? Building Research and Information 42(2):191-201. http://dx.doi.org/10.1080/09613218.2014.850602

Walker, B., C. S. Holling, S. R. Carpenter, and A. Kinzig. 2004. Resilience, adaptability and transformability in social-ecological systems. Ecology and Society 9(2):5. http://dx.doi.org/10.5751/ ES-00650-090205

Walker, B., and D. Salt. 2006. Resilience thinking: sustaining ecosystems and people in a changing world. Island Press, Washington, D.C., USA.

Wenger, C. 2015a. Building walls around flood problems: the place of levees in Australian flood management. Australian Journal of Water Resources 19(1):3-30. [online] URL: http://www. tandfonline.com/doi/abs/10.7158/13241583.2015.11465453

Wenger, C. 2015b. Better use and management of levees: reducing flood risk in a changing climate. Environmental Reviews 23 (2):240-255. http://dx.doi.org/10.1139/er-2014-0060

Wenger, C. 2017. Technical report: translating resilience theories into disaster management policies. Report No.251.2017. Bushfire and Natural Hazards Cooperative Research Centre, Melbourne, Australia. [online] URL: https://www.bnhcrc.com.au/publications/ biblio/bnh-3570

Wenger, C., K. Hussey, and J. Pittock. 2013. Living with floods: key lessons from Australia and abroad. National Climate Change Adaptation Research Facility, Gold Coast, Australia. [online] URL: https://www.nccarf.edu.au/publications/living-floods-keylessons-australia-and-abroad

Western, M., and J. Kellett. 2014. Coastal settlements adaptation study: Thompson Beach framework report. University of South Australia, Adelaide, Australia. [online] URL: http://www. mallala.sa.gov.au/webdata/resources/files/D14\%2021153\%20\%

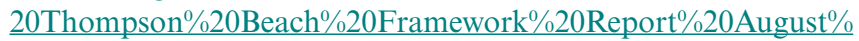
202014.pdf

White House. 2013. Executive Order - preparing the United States for the impacts of climate change. United States President, The White House, Office of the Press Secretary, Washington, D.C., USA. [online] URL: https://www.whitehouse.gov/the-pressoffice/2013/11/01/executive-order-preparing-united-states-impactsclimate-change

Wildavsky, A. 1988. Searching for safety. Transaction Books, London, UK.

Wise, R. M., I. Fazey, M. Stafford Smith, S. E. Park, H. C. Eakin, E. R. M. Archer Van Garderen, and B. Campbell. 2014. Reconceptualising adaptation to climate change as part of pathways of change and responses. Global Environmental Change 28:325-336. http://dx.doi.org/10.1016/j.gloenvcha.2013.12.002

Wolsink, M. 2006. River basin approach and integrated water management: governance pitfalls for the Dutch space-wateradjustment management principle. Geoforum 37(4):473-487. http://dx.doi.org/10.1016/j.geoforum.2005.07.001
Zebrowski, C. 2013. The nature of resilience. Resilience: International Policies, Practices and Discourses 1(3):159-173. http://dx.doi.org/10.1080/21693293.2013.804672

Zevenbergen, C., S. van Herk, J. Rijke, P. Kabat, P. Bloemen, R. Ashley, A. Speers, B. Gersonius, and W. Veerbeek. 2013. Taming global flood disasters. Lessons learned from Dutch experience. Natural Hazards 65(3):1217-1225. http://dx.doi.org/10.1007/ $\underline{\text { s11069-012-0439-3 }}$ 


\section{Appendix 1: the revised PPRR framework used in this study}

Framework 'categories' are in caps (e.g., ANTICIPATE) and 'activities' are in sentence case (e.g., Vulnerability mapping). Activities comprise measures linked to disaster resilience by case study sources and include concepts such as 'shared responsibility'.

\section{ANTICIPATE}

Vulnerability mapping and assessment; vulnerability or resilience indicators

Hazard information (e.g., flood studies, modelling, mapping, disaster loss data); consistent methodologies; accessibility

Hazard monitoring, forecasting and warning systems

Climate change adaptation strategies (may specify qualities such as: long-term view; iterative; flexible; no regrets; robust)

Risk assessment; risk management assessment and plans

Decision support systems for avoiding / mitigating (including access to information, tradeoff and synergy evaluation)

Investigate / understand underlying disaster causes $^{\dagger}$ (e.g., inequity; population growth; climate change; land degradation; human intervention; terms of trade; urbanisation)

Foster an adaptive learning culture (e.g., Research, innovation; post-disaster review; reassess strategies, values, institutions; lesson learning)

\section{AVOID}

Land use planning and management, land use zoning and enforcement

Land use change (as part of urban renewal or transition)

Climate change mitigation to avoid increased disaster risk (emissions reduction / sequestration)

\section{EXPOSURE REDUCTION}

[subset: ENGINEERING STRUCTURES]

Flood barriers (e.g., levees, flood gates)

Diversion (e.g., channels)

Artificial flood storage (e.g., flood storage dams)

Rapid drainage (e.g., deeper, wider, concreted, straightened drains; backflow prevention;

vegetation removal)

Channel / foreshore stabilization (e.g., concrete lining, groynes)
Energy dissipation structures (e.g., bulkheads, breakwaters, artificial reefs)

\section{EXPOSURE REDUCTION}

[subset: INCREMENTAL IMPROVEMENT]

[of engineered structures] Improved design; heightening; whole system planning; administration; maintenance; financing; operation; education; legislation; enforcement

\section{ACCOMMODATE}

\section{[subset: BUILT ENVIRONMENT]}

Resistant construction standards; enforcement (e.g., water or wind velocity; fire; quake; floodproofing)

Accommodating construction standards; enforcement (e.g., raised above; water flow below; moveable; temporary)

Urban design (e.g., SUDS evacuation routes; zoning and standards for flood compatibility, including critical infrastructure, hazardous substances)

\section{ACCOMMODATE}

[subset: ECOSYSTEM BASED]

Reduced reliance on structural approaches; an appropriate balance

'Living with Floods': mindset of working with ecological processes (rather than fighting them)

Room for rivers to flood; expand area for temporary flooding; dyke removal or relocation; reconnect floodways

Protecting / enhancing natural flow paths and flood buffers: wetlands, riparian and coastal ecosystems

IWRM, co-benefits, multiple use and supporting governance arrangements

Regional / catchment-based data and planning

Basin land management (e.g., erosion control; permeability; agricultural practices)

Public education / understanding of hydrology, ecosystems, catchment / human interactions 


\section{ACCOMMODATE}

[subset: PREPARE]

Awareness of risks and knowledge of what to do before and during an emergency

Foster adaptive capacity through allowing exposure to hazard or disturbance

Capacity building (e.g., fostering networks; partnerships; volunteering; stakeholder participation; empowerment; sharing knowledge, skills, information, resources, technology)

Shared responsibility (individuals, businesses, communities, governments); self-reliance; safety behavioral / cultural change

Reducing vulnerability of disadvantaged groups (e.g., social equity; health; education; inclusion; land tenure; sustainable development; food security)

Institutional arrangements (e.g., agencies, leadership, roles, responsibilities, coordination; accountabilities; policy integration; laws; incentives; funding; investment policies; before, during, after disasters)

Business continuity planning; capacity of critical infrastructure and services to function in disasters; redundancy; substitutability

Multi-hazard disaster management planning (e.g., by households, business, public sector and emergency management agencies)

Evacuation planning, infrastructure and supplies

Planning for/preventing disaster-related epidemics

Recovery planning

Anticipatory transformational recovery planning; windows of opportunity

\section{RESPOND}

Information and communication systems, strategies

Response capacity, capability and flexibility (local and scaled-up; staff; equipment; emergency supplies; skills; shelters; operation centres; interoperability and redundancy)

Drills and scenario simulations, training

Decision support systems for response management

Volunteer recruitment, training and support

\section{RECOVER}

\section{[subset: ASSESSMENT AND FUNDING]}

Financing recovery (e.g., insurance; maintaining insurance affordability / availability; charity; public relief and recovery funding; 'risk sharing' compensation; loans; subsidies; local labour; mitigation incentives)

Post-disaster needs assessment; local participation

\section{RECOVER}

\section{[subset: BOUNCE BACK TO PRE-EXISTING} STANDARDS]

Rapid rebuild to prior standards

Non-financial recovery support (e.g., long term health; rebuilding communities)

Recovery of existing industries

Ecosystem recovery

\section{RECOVER}

[subset: INCREMENTAL IMPROVEMENT] Improved rebuild or post-disaster upgrade Adjustment of existing industries; diversification:

\section{RECOVER}

[subset: TRANSFORMATIONAL CHANGE]

Relocation; land use change (as part of recovery) $\$$

New, flood compatible industries; alternative livelihoods:

Recovery targeting long term improvements for the most vulnerable

$\uparrow$ Transformational approaches often address underlying causes. For inclusion in this activity, the document had to either recommend this be done or the document itself provide an examination of one or more underlying cause. Documents that merely listed underlying causes in a preamble or rationale were not included (else this activity would be meaningless as most policy documents include a brief rationale).

$\$$ These are 'build back better' activities that have greatest chance of uptake following a disaster. However, they may also be pre-emptive strategies initiated outside the recovery phase. Voluntary relocation, in particular, tends to be a measure implemented over many decades. Alternative livelihoods is a form of land use change aimed at both avoiding flood damage (abandoning the previous flood-susceptible land use) and accommodating floods (through the new flood-tolerant land use). Diversification could be pursued as a continuity strategy (accommodate: prepare) undertaken on an individual business or broader economic scale. The recovery phase is sometimes used as a 'window of opportunity' to implement these changes (this generally requires pre-planning and supportive institutional arrangements as the opportunity is brief). 